\title{
Trace elements in seminal plasma of men from infertile couples
}

\author{
Wojciech Guzikowski ${ }^{1}$, Małgorzata I. Szynkowska², Hanna Motak-Pochrzęst ${ }^{3}$, \\ Aleksandra Pawlaczyk², Stanisław Sypniewski²
}

${ }^{1}$ Obstetric, Gynecology and Neonatal Hospital, Opole, Poland
${ }^{2}$ Institute of General and Ecological Chemistry, Technical University of Lodz, Lodz,
Poland
${ }^{3}$ Obstetric and Gynecology Department, District Hospital, Strzelce Opolskie, Poland

Submitted: 27 December 2010

Accepted: 23 July 2013

Arch Med Sci 2015; 11, 3: 591-598

DOI: $10.5114 /$ aoms.2015.52363

Copyright $\odot 2015$ Termedia \& Banach

\section{Abstract}

Introduction: An analysis of lead, zinc, cadmium and other trace elements in semen of men from infertile couples was performed to determine the association between abnormal semen parameters and enviromental or occupational exposure to some trace metals.

Material and methods: Presence of manganese, cobalt, nickel, copper, zinc, molybdenum, cadmium, tin and lead was measured in seminal plasma of 34 men from infertile couples using spectrometry with time-of-flight analysis. Correlations among sperm parameters and trace metals were determined using cluster analysis and Pearson's correlation coefficient.

Results: Abnormally high concentrations of lead, cadmium, zinc and cobalt were found in 23 seminal plasma of men from infertile couples. The most consistent evidence was determined for an association between high cadmium concentration in seminal plasma and sperm count, motility and morphology below reference limits $(p<0.01)$. A correlation of significantly increased tin level and reduced sperm count in semen of men with limited fertility potential was observed $(p=0.04)$.

Conclusions: In our study we observed a correlation of tin level with sperm count in semen of men with limited fertility potential.

Key words: trace elements, infertility, seminal plasma.

\section{Introduction}

Infertility affects about $8 \%$ to $12 \%$ of the world's population and in about half of the cases men are either the single cause of or contribute to the couple's infertility. The decline of semen quality might be caused by environmental factors, occupational exposure, nutritional, socioeconomic or other unknown causes [1]. Previous reports have taken into consideration mostly the semen parameters such as sperm volume, concentration and total sperm count and then motility or morphology of spermatozoa. Trace elements may play an important role in the male reproductive process because of their high activity at the molecular level although they are known to exist in the body at very low levels. The relationships between element concentrations in semen and sperm parameters have been investigated by many authors [2, 3]. The general population is exposed to metals at low concentrations either voluntarily
Corresponding author:

Wojciech Guzikowski MD, PhD Obstetric, Gynecology and Neonatal Hospital 8 Reymonta St

45-066 Opole, Poland Phone: +48 (77) 4545401

Fax: +48 (77) 4545408

E-mail: habibi48@op.pl 
through supplementation or involuntarily through intake of contaminated food, water or contact with contaminated soil, dust or air. Global declines in semen quality were suggested to be associated with increased exposure to environmental chemicals that act as endocrine disrupters as a result of increased use of pesticides, plastics and other anthropogenic materials $[4,5]$. The etiology of abnormal semen characteristics may involve unknown environmental and occupational factors. New assisted reproduction techniques have generated insufficient interest in better understanding the etiologies of male infertility and possibilities for preventing them.

The cement industry is one of the main branches of the economy conditioning development of the Province of Opole. Investigations showed the increase in the content of some trace elements including lead, zinc and cadmium in areas situated close to the cement plants (Odra and Groszowice). In addition, higher accumulation of metals was found in soils next to the Odra cement plant.

We decided to perform an analysis of some trace elements in semen of men from infertile couples in the rural area of Opole. The study was designed to determine whether there is an association between abnormal semen parameters and environmental or occupational exposure to some trace metals in the area of Opole.

\section{Material and methods}

The group consisted of 34 men from primary infertile couples in the rural area of Opole, without any previous treatment, who had regular unprotected intercourse for at least 12 months without conception with their partners. The study was carried out in the andrology consulting room in the Obstetric, Gynecology and Neonatal Hospital in Opole between $1^{\text {st }}$ January 2009 and $30^{\text {th }}$ June 2009. The patients' age ranged between 26 and 42 years, and mean age was 28.9.

All of the women of infertile couples had normal standard medical and gynecological examinations. All these women were investigated to exclude the known causes of infertility: clinical and laboratory examination, family history, age, body mass index (BMI), genetic abnormalities (both the women and their partners also had karyotype analysis), congenital and acquired anatomic abnormalities of uterus (hysterosalpingography and/or hysteroscopy, pelvic ultrasonography), endocrinopathies (luteal phase insufficiency, polycystic ovary syndrome, insulin resistance and hyperandrogenism, diabetes mellitus, thyroid and prolactin disorders) in the result of hormonal studies (LH, FSH, TSH, PRL, estradiol, testosterone), pelvic inflammatory diseases (in the result of CRP test, cervical mucus inoculation, $\mathrm{pH}$ of vaginal dis- charge), and environmental factors (toxins, alcohol, cigarettes, caffeine).

In all of the women of infertile couples the following parameters were tested: biphasic cycles (checked by basal body temperature), folliculometry (checked by ultrasonographic measurements), cervical mucus appearance, lack of any signs of an infection of all the genital tract (on the basis of laboratory tests), normal hysterosalpingography and normal hormonal tests.

Men who had undergone pelvic surgery of hernia repair, varicocele repair, with diabetes mellitus and thyroid disturbances, infections, endocrine hypogonadism, history of chemotherapy, radiation therapy, and sexual dysfunction were excluded from the study. Patients who were on antipsychotic drugs or taking alcohol, vitamin or mineral supplementation were excluded from the study. The Institutional Review Board for Clinical Investigation approved the study and informed consent was taken from all participants.

Semen samples were obtained by masturbation into $50 \mathrm{ml}$ sterile jars after an abstinence period of 5 days. After liquefaction, samples were processed by conventional analysis to determine the volume, $\mathrm{pH}$, sperm count, sperm motility and sperm morphology according to WHO criteria [6].

Seminal fluid was measured with a $5 \mathrm{ml}$ calibrated syringe. Sperm motility was assessed by measuring a drop of semen on a covered slide at 400-600x magnification. Semen analyses were obtained from the hospital laboratory, providing assessments according to standardized methodologies, based on World Health Organization (WHO) criteria [6].

The seminal plasma was collected in fresh tubes and stored at $-20^{\circ} \mathrm{C}$ until used for trace metal assay in the Institute of General and Ecological Chemistry in the Technical University of Lodz, Poland.

\section{Measurement of metals}

All samples of semen before the sample preparation stage were stored in the fridge. Digestion of biological material was carried out using ultra pure nitric acid purchased from Baker. In order to achieve complete mineralization each sample (approximately $0.2-0.4 \mathrm{ml}$ ) was placed in closed Teflon vessels with $2 \mathrm{ml}$ of concentrated nitric acid and digested in a microwave oven system, Milestone MLS-1200 MEGA. The digestion conditions are presented in Table I. Before opening the vials the Teflon vessels were placed for $45 \mathrm{~min}$ in the freezer. At the end of the digestion process biological samples were diluted to a final volume of $10 \mathrm{ml}$ with demineralized Milli-Q water. The measurement of presence of heavy metals, especially, in studied material was performed with inductively coupled plasma mass spectrometry technique 
with a time-of-flight analyzer (ICP-ToF-MS), Optimass 8000 GBC (Australia). The working parameters were optimized based on the analysis of pure grade solution containing elements from the light, average and heavy mass range at the $10 \mathrm{ppb}$ level. All ICP-MS operating parameters were adjusted to give a maximum signal for selected analyzed isotopes and a minimum signal at the same time for double charged elements or creating oxides.

The following selected trace elements were analyzed: manganese $55\left({ }^{55} \mathrm{Mn}\right)$, cobalt $59\left({ }^{59} \mathrm{Co}\right)$, nickel $60\left({ }^{60} \mathrm{Ni}\right)$, copper $63\left({ }^{63} \mathrm{Cu}\right)$, zinc $66\left({ }^{66} \mathrm{Zn}\right)$, molybdenum 98 ( $\left.{ }^{98} \mathrm{Mo}\right)$, cadmium $111\left({ }^{111} \mathrm{Cd}\right)$, tin $118\left({ }^{118} \mathrm{Sn}\right)$, lead $208\left({ }^{208} \mathrm{~Pb}\right)$.

In order to examine the characteristic groups of selected trace metals and the morphology of semen the data were submitted to chemometric analysis.

\section{Statistical analysis}

Statistical analysis was performed using Statistica software version 8 . Bivariate analysis was conducted between semen quality and presence of all metals. Correlations or differences between groups were tested statistically using parametric or nonparametric methods with Student's $t$ test (or the Mann-Whitney test when the requirements for the $t$ test were violated). A $p$ value $\leq 0.05$ was taken as statistically significant. A cluster analysis was applied to the data sets using the Euclidean distance between objects as a measure of similarity. Ward's method was used as an agglomerative hierarchical clustering procedure. The main results of clustering by Ward's method were similar to those obtained by other hierarchical methods such as weighted or unweighted average linkage. For all of the patients, Pearson's correlation coefficient was used and the strength of the correlations was estimated as: low $0<r<0.1$, weak $0.1<r<0.3$, average $0.3<r<0.5$, high $0.5<$ $r<0.7$, very high $0.7<r<0.9$ and almost perfect for $0.9<r<1.0$.

Multivariate techniques of principal component analysis (PCA) and cluster analysis (CA) were employed to identify possible sources of the selected metals in the semen of the two groups of patients: 1) with normal parameters of sperm concentration, motility and morphology (11 patients); 2) with parameters below the reference values (23 patients).

\section{Results}

Semen analysis results from the group of men with limited fertility potential according to the sperm concentration, motility and presence of abnormal forms are shown in Figure 1.

In our data from the semen analysis we found that over $80 \%$ of men of infertile couples had an
Table I. Cycles of biological sample mineralization in microwave oven MILESTONE MLS-1200 MEGA

\begin{tabular}{|lcc|}
\hline Cycle & Mineralization time [min] & Power [W] \\
\hline 1 & 2 & 250 \\
\hline 2 & 2 & 0 \\
\hline 3 & 6 & 250 \\
\hline 4 & 5 & 400 \\
\hline 5 & 5 & 600 \\
\hline Ventilation 5 min & & \\
\hline
\end{tabular}

abnormality of at least one semen parameter. $42.4 \%$ of these men (group I) had a sperm concentration of $<20 \times 10^{6} \mathrm{sperm} / \mathrm{ml}$.

The data showed low motility $(<50 \%)$ of semen in $78.7 \%$ of patients. Analysis of semen morphology data revealed that about $84 \%$ of men with limited fertility potential showed $<15 \%$ abnormal forms.

Patients were divided into two groups according to the following criteria: the first group with a sperm concentration $<20 \times 10^{6} \mathrm{ml}$, $<50 \% \mathrm{mo}$ tile sperm or $<15 \%$ normal forms, and the second, reference group comprising patients with a sperm concentration $>20 \times 10^{6} \mathrm{ml}$, >50\% motile sperm and $>15 \%$ normal forms. The first group consisted of 23 men with semen parameters below reference values, and the second group consisted of 11 men with semen parameters within the normal range.

Semen parameters such as sperm count and motility differ significantly among the two groups, as shown in Figure 2.

The basic statistical distribution parameters related to the trace metal concentrations in the semen of men from infertile couples are presented in Table II.

The cluster analysis of the data pertaining to men from infertile couples according to their semen parameters is presented in the form of a dendrogram in Figure 3. In the semen of men with limited fertility potential, strong clustering is observed among normal morphology-motility-sperm count, $\mathrm{Pb}-\mathrm{Cd}$, Zn-Co, Sn-Cu-Ni-Mn. From Figure $3 \mathrm{~B}$ and at a distance of 7 , three clusters can be seen, the first one (beginning from the left) composed of metals ( $\mathrm{Pb}, \mathrm{Cd}, \mathrm{Mo}$ ), the second cluster formed by morphology and motility, and the third cluster formed by other trace elements ( $\mathrm{Zn}, \mathrm{Sn}, \mathrm{Cu}$, $\mathrm{Co}, \mathrm{Ni}, \mathrm{Mn}$ ) and sperm count. From Figure $3 \mathrm{C}$ at a distance of 7 , only two main clusters can be seen. Moving from the left to the right, the first is formed by parameters of semen quality (morphology, motility, sperm count), while the second cluster can be considered as composed mainly of trace metals: $\mathrm{Zn}-\mathrm{Co}, \mathrm{Pb}-\mathrm{Cd}$, Sn-Mo-Cu-Ni-Mn.

Correlations between selected trace metals and sperm parameters (sperm count, sperm mo- 


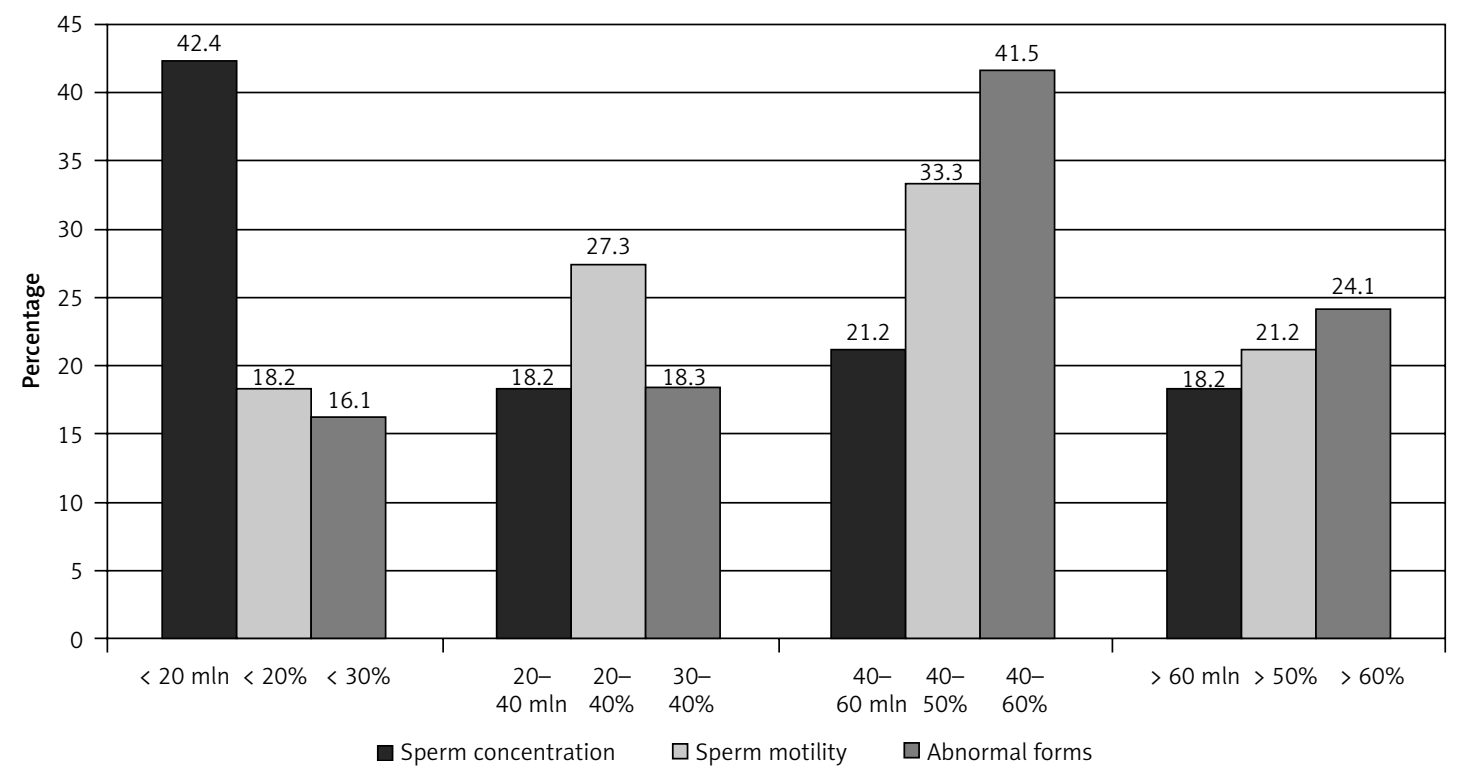

Figure 1. Sperm concentration $\left(\times 10^{6} / \mathrm{ml}\right)$, sperm motility $(\%)$ and abnormal forms $(\%)$ in semen of men from infertile couples $(n=34)$

A

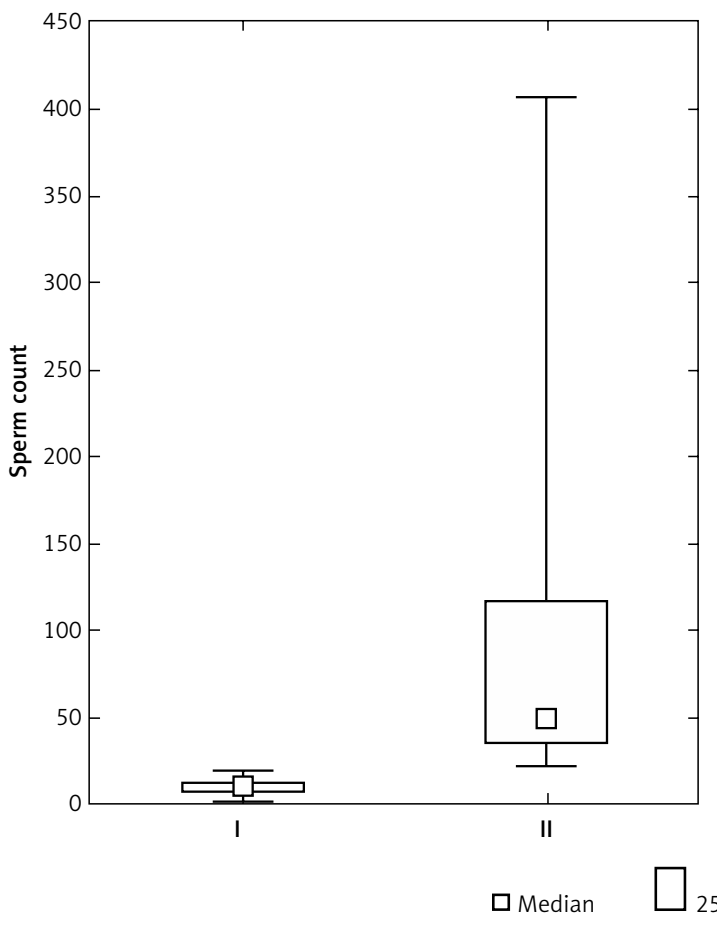

B

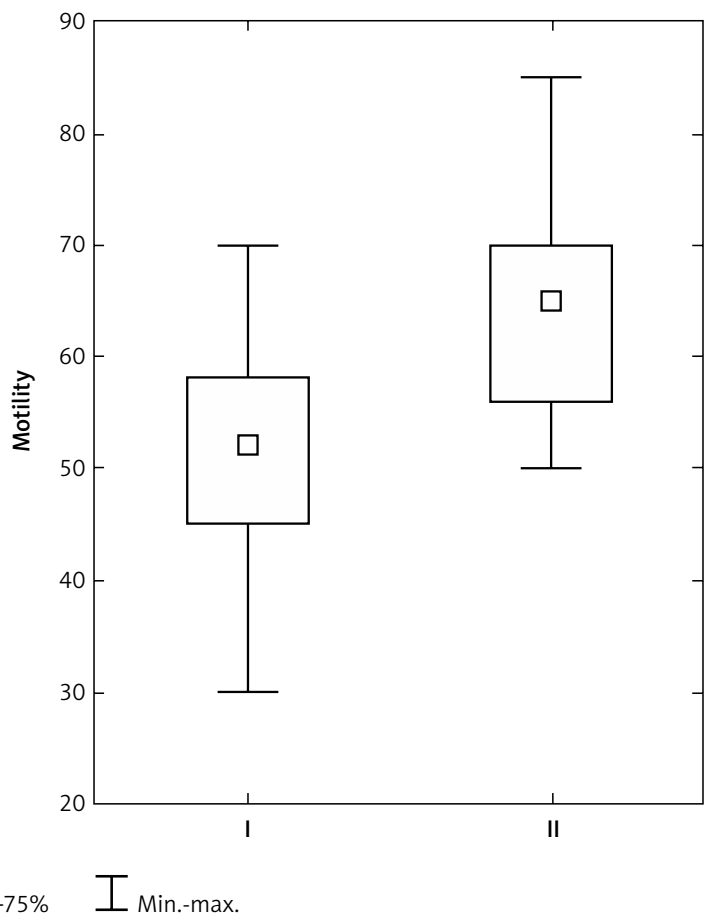

Figure 2. Sperm counts (A) and motility (B) in two groups of men: I - with semen parameters below the reference values and II - with normal semen parameters

tility and sperm morphology) are presented in Table III.

Pearson's correlation coefficient $(r)$ indicates significant correlations between all the semen parameters including sperm count, motility, morphology and cadmium levels. A significant correlation is observed also between sperm count and tin levels in semen. An examination of the data revealed significant differences between groups I and II for cadmium $(p<0.01)$ and tin levels $(p=0.04)$ in semen.

After comparing zinc and cadmium levels in semen, we found statistical differences relating to the two analyzed groups - as shown in Figure 4.

Zinc levels are similar in groups I and II, but cadmium levels revealed significant differences between the two groups with a positive correlation with abnormal sperm parameters. 


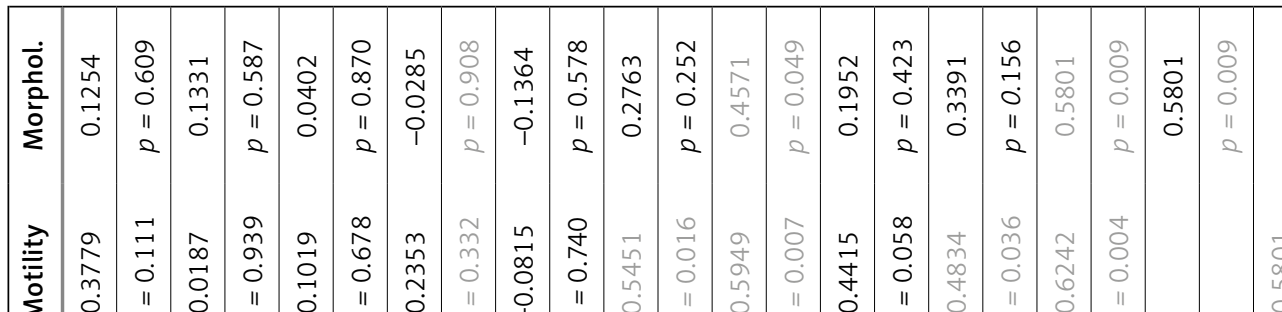

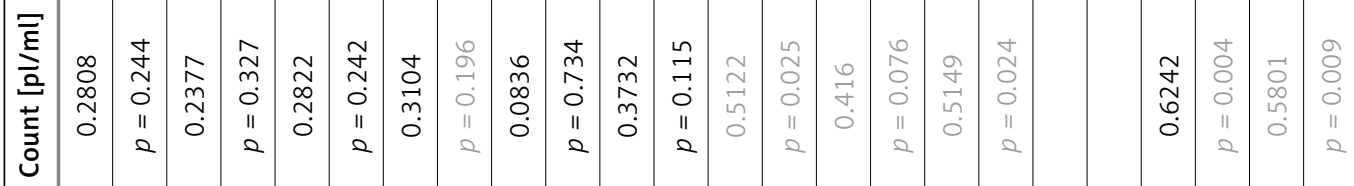

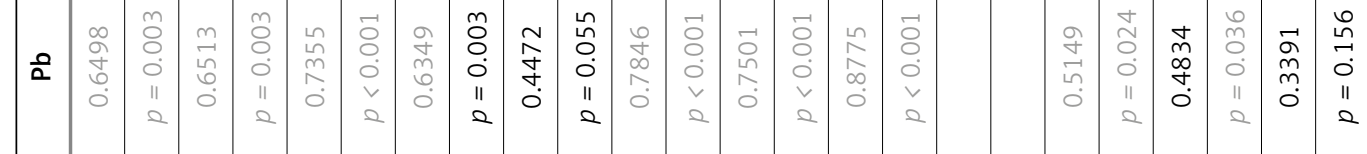

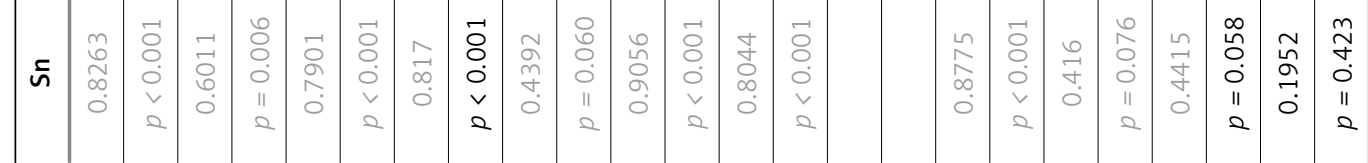

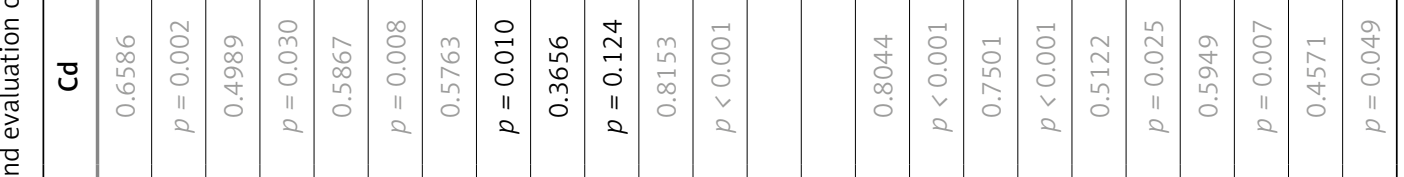

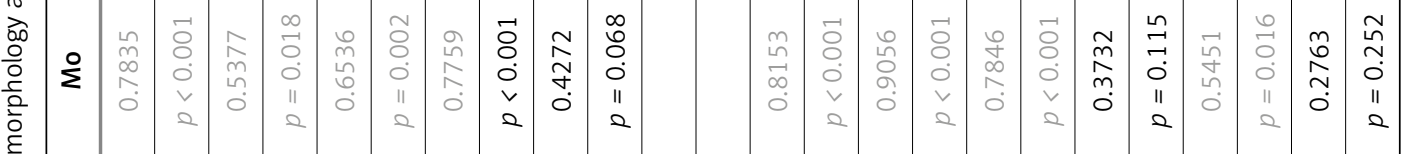

i

辛

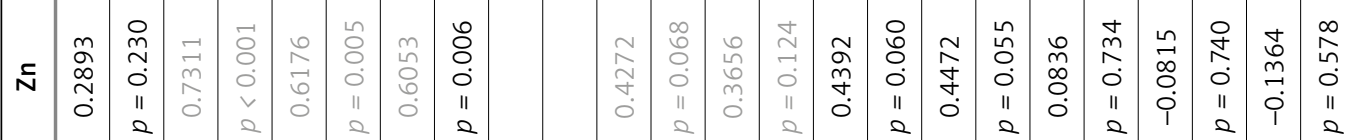

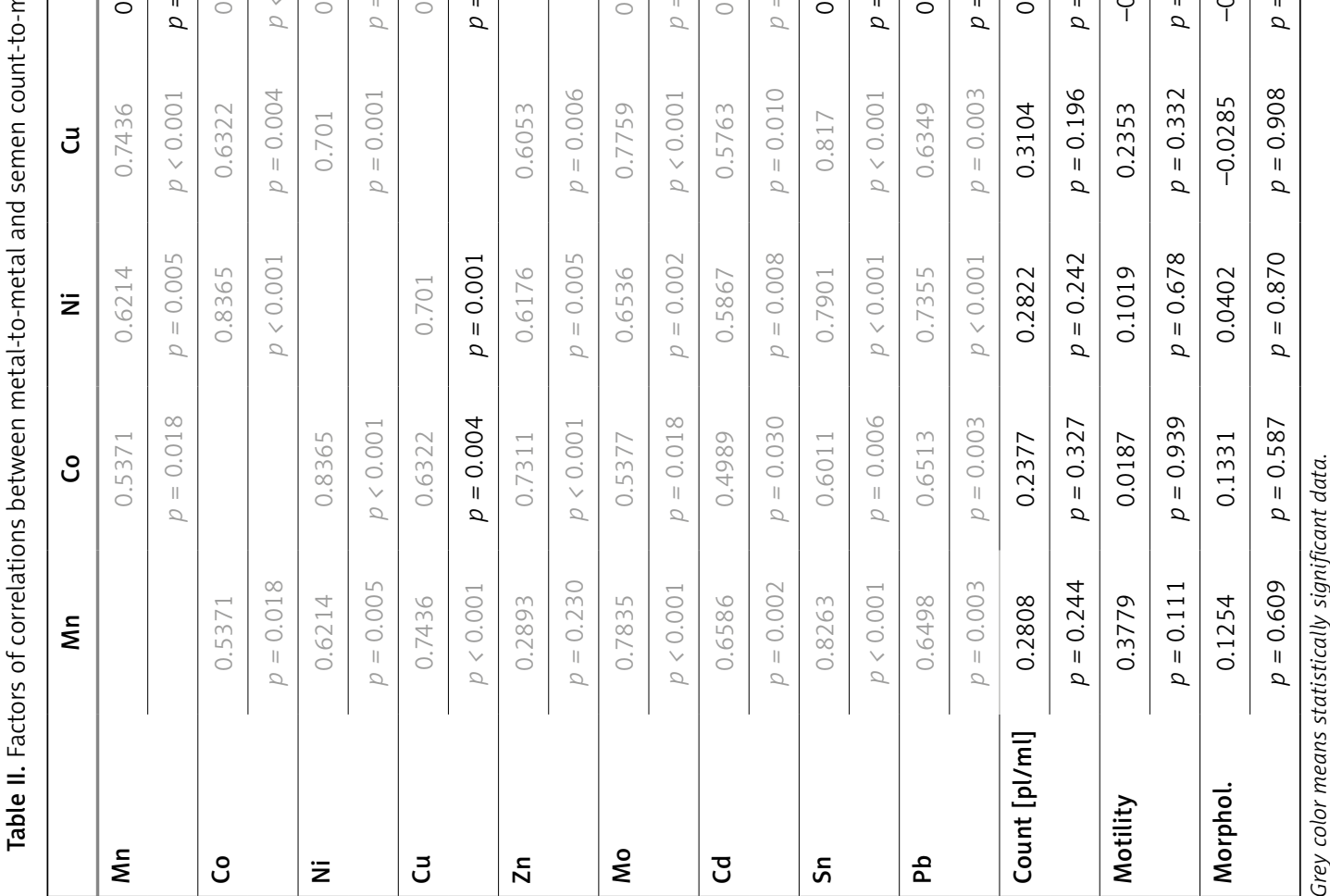




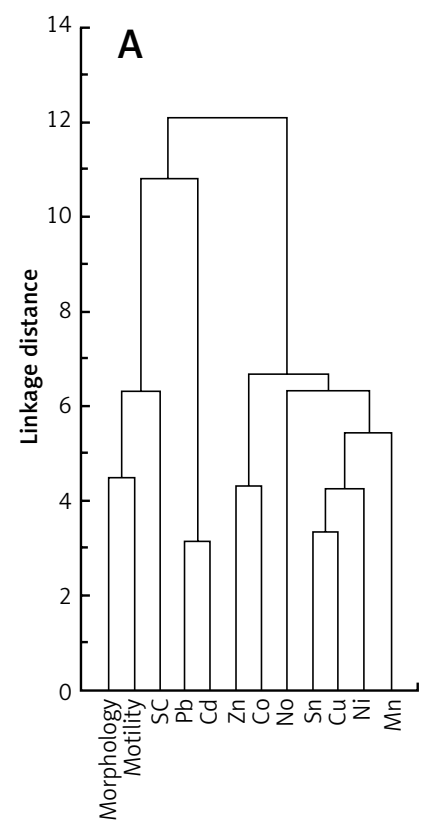

B

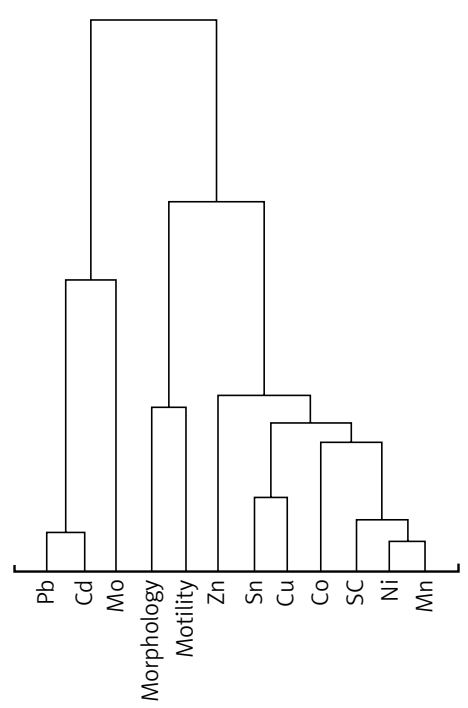

C

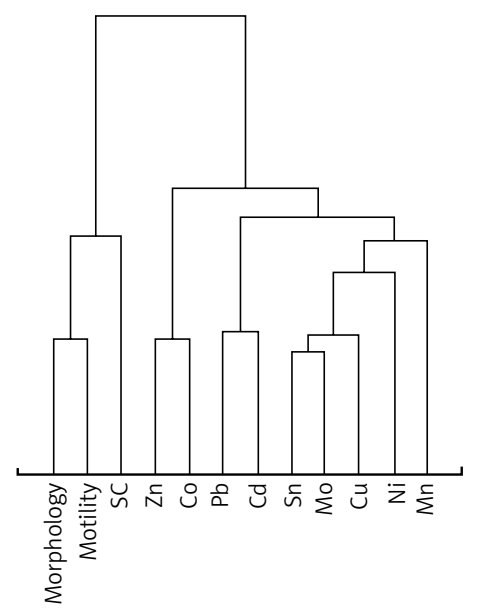

Figure 3. Cluster analysis of selected metals in semen of 34 men from infertile couples (A), 23 men with semen parameters below reference limits (B) and 11 men with semen parameters within normal ranges (C)

Table III. Correlations between trace metals and sperm counts, sperm motility and sperm morphology in semen of men from infertile couples $(n=34)$

\begin{tabular}{|lccc|}
\hline $\begin{array}{l}\text { Trace } \\
\text { element }\end{array}$ & $\begin{array}{c}\text { Sperm } \\
\text { count }(r)\end{array}$ & $\begin{array}{c}\text { Sperm } \\
\text { motility }(r)\end{array}$ & $\begin{array}{c}\text { Sperm } \\
\text { morphology }(r)\end{array}$ \\
\hline $\mathrm{Mn}$ & 0.27 & 0.27 & 0.21 \\
\hline $\mathrm{Co}$ & 0.20 & -0.10 & 0.03 \\
\hline $\mathrm{Ni}$ & 0.26 & 0.01 & -0.01 \\
\hline $\mathrm{Cu}$ & 0.25 & 0.11 & 0.06 \\
\hline $\mathrm{Zn}$ & 0.07 & -0.06 & 0.09 \\
\hline $\mathrm{Mo}$ & 0.32 & 0.19 & 0.15 \\
\hline $\mathrm{Cd}$ & 0.51 & 0.35 & 0.36 \\
\hline $\mathrm{Sn}$ & 0.34 & 0.31 & 0.26 \\
\hline $\mathrm{Pb}$ & 0.32 & 0.32 & 0.35 \\
\hline
\end{tabular}

$r$-Pearson's correlation coefficient.

\section{Discussion}

Many microelements such as zinc, copper, iron, manganese and cadmium have some known effects on semen quality. Since the 1980s, the influences of trace elements on semen quality and male factor infertility have been taken more seriously. Seminal plasma zinc concentration was noted to be statistically significantly correlated with sperm density, motility and viability $[7,8]$. In our data we found no correlations between zinc levels in seminal plasma and sperm parameters. In the literature a significant positive correlation was observed between zinc levels and sperm count [9]. Hasan et al. [2] found a significant positive relationship between sperm density and seminal plasma zinc concentration in fertile, but not infertile men. The infertile men with antisperm antibodies or counts greater than $20 \mathrm{million} / \mathrm{ml}$ had significantly higher levels of seminal plasma zinc than infertile men with oligozoospermia. The absence of significant differences between fertile and infertile men suggests that investigations of seminal plasma zinc and copper levels has a small clinical value.

Some trace elements such as calcium, magnesium, zinc and copper play an essential role in spermatogenesis and fertility, but other trace elements such as cobalt could influence infertility. Copper, zinc and molybdenum are involved in many biochemical processes supporting life, including cellular respiration, DNA and RNA reproduction, and maintenance of cell membrane integrity. On the other hand, excess intake of these trace elements may lead to diseases and toxicity $[5,10]$.

Similarly as in the study of Chia et al. [7], we noted no differences between concentrations of zinc and copper in the two groups of fertile men and men from infertile couples. Significant correlations observed in the literature between blood cadmium levels, volume of semen and immature forms of spermatozoa suggest that further studies on cadmium levels in the blood or in the semen are needed, especially in the group of cigarette smoking men. In our study positive correlations between cadmium levels in seminal plasma and abnormal sperm count, sperm motility and morphology were observed. 
A

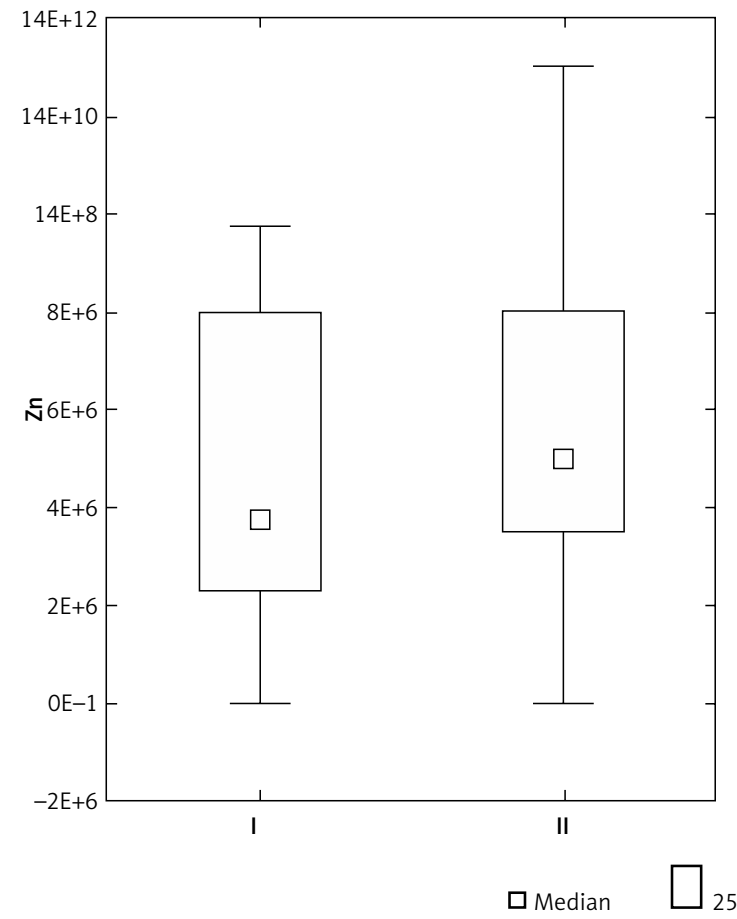

B

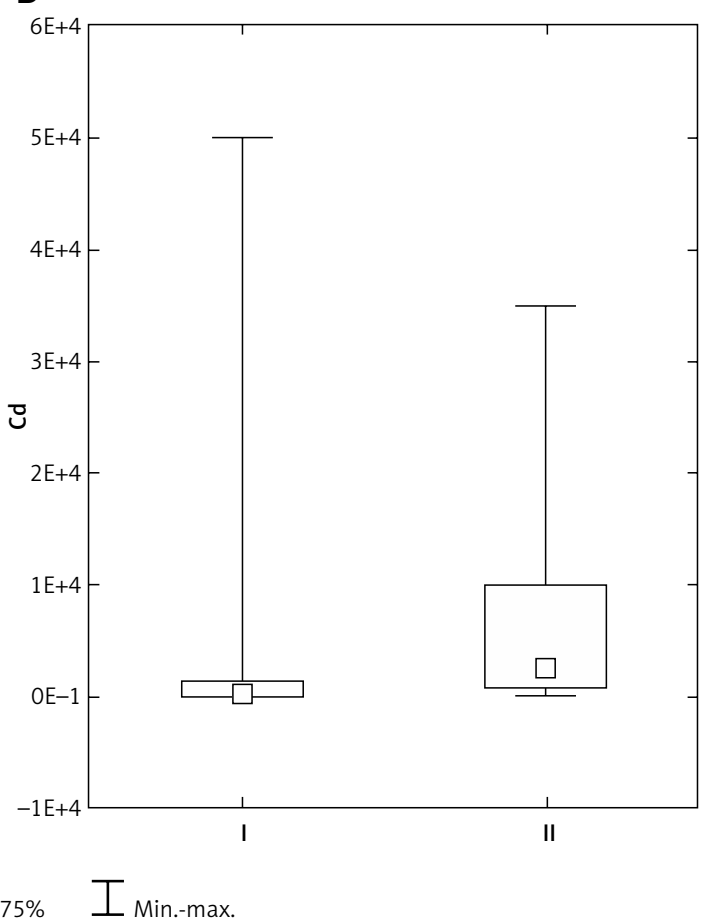

Figure 4. Median zinc (A) and cadmium (B) levels in semen in two groups of men: I - with semen parameters below the reference values and $\mathrm{II}$ - with normal semen parameters

Some authors [11] did not find relationships between sperm parameters and trace element levels besides selenium, in seminal plasma. An increase in lead and cadmium levels was observed in men from infertile couples, and there was a significant negative correlation of cadmium and lead semen concentration with sperm motility and sperm concentration in oligozoospermia [12-15]. In the semen of men with limited fertility potential, strong clustering was observed among normal morphology-motility-sperm count, some trace elements such as lead with cadmium, zinc with cobalt and others such as tin, copper, nickel and manganese.

We also found that tin level was correlated with sperm count, but not with sperm motility and morphology.

Additionally it should be speculated that although the emissions of cement pollution in the Province of Opole have declined during recent years, they are more intrusive because of acid rain caused by incomparably higher emissions of toxic elements in the atmosphere. Deterioration of sperm parameters, apart from known reasons, may be influenced by pollution from the cement industry. Our data represent a pilot study and further investigations are needed.

In conclusion, in the semen of men from infertile couples in the rural area of Opole we found correlations among semen parameters and lead-cadmium and zinc-cobalt levels in seminal plasma. Among a number of suggestive relationships be- tween some trace metals and semen parameters that we observed in the present study, we found the most consistent evidence for an association between cadmium concentration in seminal plasma and sperm count, motility and morphology. In our study we observed a correlation between tin level and sperm count in seminal plasma of men with limited fertility potential.

\section{Conflict of interest}

The authors declare no conflict of interest.

\section{References}

1. Kasperczyk A, Dobrakowski M, Horak S, Zalejska-Fiolka J, Birkner E. The influence of macro and trace elements on sperm quality. J Trace Elem Med Biol 2015; 30: 153-9.

2. Hasan A, Ahmed M, Baig M, Ali M. Relationship of zinc concentration in blood and seminal plasma with various semen parameters in infertile subjects. Pakist J Med Sci 2007; 23: 111-4.

3. Jeng HA, Huang YL, Pan CH, Diawara N. Role of low exposure to metals as male reproductive toxicants. J Environ Health Res 2015; 25: 405-17.

4. Pant N, Pant AB, Chaturvedi PK, et al. Semen quality of environmentally exposed human population: the toxicological consequence. Environ Sci Pollut Res Int 2013; 20: 8274-81.

5. Wong EW, Cheng CY. Impacts of environmental toxicants on male reproductive dysfunction. Trends Pharmacol Sci 2011; 32: 290-9. 
6. World Health Organization. Laboratory manual for the examination of human semen and sperm-cervical mucus interaction. 4th ed. Cambridge University Press, Cambridge 1999.

7. Chia SE, Ong CN, Chua LH, Ho LM, Tay SK. Comparison of zinc concentration in blood and seminal plasma and the various sperm parameters between fertile and infertile men. J Androl 2000; 21: 53-7.

8. Colagar AH, Marzony ET, Chaichi MJ. Zinc levels in seminal plasma are associated with sperm quality in fertile and infertile men. Nutr Res 2009; 29: 82-8.

9. Türk S, Mändar R, Mahlapuu R, Viitak A, Punab $M$, Kullisaar T. Male infertility: decreased levels of selenium, zinc and antioxidants. J Trace Elem Med Biol 2014; 28: 179-85.

10. Li Y, Gao Q, Li M, Li M, Gao X. Cadmium, chromium, and copper concentration plus semen-quality in environmental pollution Site, China. Iran J Public Health 2014; 43: 35-41.

11. Ahsan U, Kamran Z, Raza I, et al. Role of selenium in male reproduction - a review. Anim Reprod Sci 2014; 146: 55-62.

12. Behne D, Gessner H, Wolters G, Brotherton J. Selenium, rubidium and zinc in human semen and semen fractions. Int J Androl 2008; 11: 415-23.

13. Kim K, Bloom MS, Kruger PC, et al. Toxic metals in seminal plasma and in vitro fertilization (IVF) outcomes. Environ Res 2014; 133: 334-7.

14. Pant N, Kumar G, Upadhyay AD, Gupta YK, Chaturvedi PK. Correlation between lead and cadmium concentration and semen quality. Andrologia 2014 Sep 16.

15. Taha EA, Sayed SK, Ghandour NM, et al. Correlation between seminal lead and cadmium and seminal parameters in idiopathic oligoasthenozoospermic males. Cent Eur J Urol 2013; 66: 84-92. 